\title{
Smart Lighting Application for Energy Saving and User Well-Being in the Residential Environment
}

\author{
Moe Soheilian*(D), Géza Fischl (D) and Myriam Aries \\ Department of Construction Engineering and Lighting Science, School of Engineering, Jönköping University, \\ 55511 Jönköping, Sweden; geza.fischl@ju.se (G.F.); myriam.aries@ju.se (M.A.) \\ * Correspondence: moe.soheilian@ju.se
}

\begin{abstract}
The idea of smart lighting has emerged over the years in commercial and industrial environments, with a focus on energy saving. With the advancement in technology, smart lighting can now offer opportunities in addition to energy saving to users in home environments for the provision of a comfortable atmosphere and the maintenance of user well-being. Currently, research in the smart lighting field is predominantly dedicated to energy saving in non-residential environments; meanwhile, the residential environments have not been explored. Therefore, a literature review was conducted to provide an overview of smart lighting systems' effect on energy and well-being in the residential environment. Current research is mostly limited to designing and developing a smart lighting system in a controlled environment, with a limited evaluation of well-being and comfort. The review shows that residential smart lighting application possibilities and opportunities are not widely and thoroughly explored.
\end{abstract}

Keywords: home environment; intelligent lighting; lighting control; energy saving; user comfort; user well-being; lighting protocol

Citation: Soheilian, M.; Fischl, G.; Aries, M. Smart Lighting Application for Energy Saving and User

Well-Being in the Residential Environment. Sustainability 2021, 13, 6198. https://doi.org/10.3390/ su13116198

Academic Editor:

Antonio Peña-García

Received: 4 May 2021

Accepted: 27 May 2021

Published: 31 May 2021

Publisher's Note: MDPI stays neutral with regard to jurisdictional claims in published maps and institutional affiliations.

\section{Introduction}

In the future, everything may be 'connected' and 'smart' in the built environment. The concept of smart lighting has emerged over the past decade in commercial and industrial environments, predominantly focusing on energy saving. From a broader perspective, smart lighting in the residential environment is a part of the 'smart home' concept where the main goal is to provide and promote user comfort, convenience, and security, and to satisfy residents' needs [1]. Rossi [2] (p. 179) defined smart lighting systems (SLS) as 'lighting systems with the ability to control, communicate and interconnect data, able to provide new ways of interacting with the luminous performances in new luminaires, equipped in turn to offer additional service'. Schubert and Kim [3] (p. 1277) defined smart lighting as 'solid-state sourcesin particular, Light Emitting Diodes (LED)-based sources-offer what was inconceivable with conventional sources: controllability of their spectral, spatial, temporal, and polarisation properties as well as their colour temperature'. In general, smart lighting systems consist of energyefficient light sources such as LEDs, a wireless communication network including software, and (optional) sensors aiming to provide optimal lighting solutions integrated with a control system [2]. A smart light bulb is an illumination source (LED system or another light source) in a housing configured to fit a conventional light fixture. Additionally, the housing contains a processor, which controls the light source's intensity and colour, and a transmitter and/or receiver to enable signal exchange with other smart devices, such as another smart light bulb or another device. The type of protocol used for (wireless) communication within the SLS is reported to have varying power use, as there are several communication protocols. The ZigBee protocol, frequently used these days, consumes less power than other protocols like Wi-Fi $[4,5]$. Hence, a network based on Wi-Fi communication only consumes more energy than if part of the data communication is done via a ZigBee protocol (see Figure 1). Protocols like Bluetooth Low Energy (BLE) have the advantage of consuming an 
even lower amount of energy but are limited in communication distance and the number of connected devices.

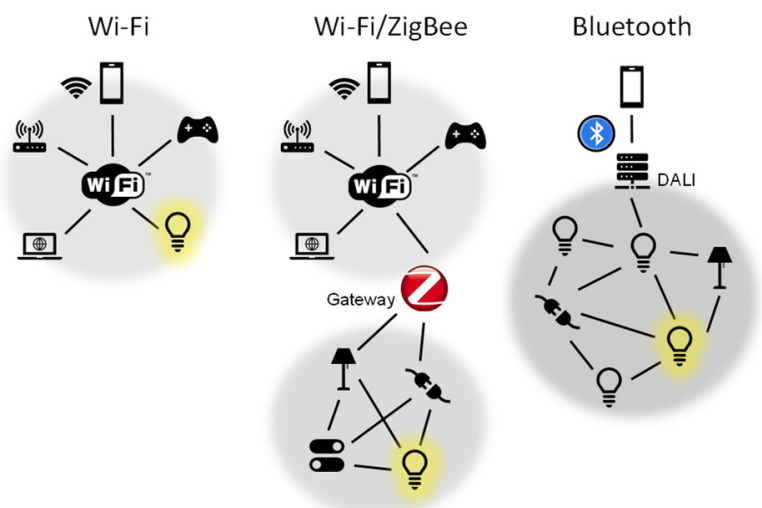

Figure 1. Examples of communication network structures: Wi-Fi, Wi-Fi combined with ZigBee, and Bluetooth Low Energy.

Recent literature reviews on smart lighting and controls showed that the application of smart lighting systems is mainly conducted in non-residential environments, focusing on energy savings [6-8]. Studies in office environments exhibited potentials for energy saving varying from 17 to $94 \%$ over traditional (manual) control systems, depending on user behaviour, activity patterns, and different types of control systems, such as daylight harvesting and occupancy control systems [6,9-15]. Control systems based on occupancysensing are commonly used for energy saving by detecting the user's motion in the targeted environment. This control system can potentially result in energy savings of 3 to $60 \%$ depending on user behaviour and activity patterns $[6,16]$. Daylight-integrated lighting control systems can be used to turn off or dim down the electric lights automatically based on the available natural light in the room to achieve a target illumination level. Studies have shown that this type of control system can typically achieve over $40 \%$ of energy saving $[11,17]$. However, their effectiveness highly depends on orientation, latitude, and window characteristics. Other types of control systems, such as schedule-based control systems, are useful when occupancy patterns are predictable and set [7]. The use of the different lighting control systems may result in significant energy savings, but occupants' behaviour, building or room properties (geometry), daylight entrance, and type of activity have substantial effects on a system's performance [7]. Even though many smart lighting studies have focused on energy saving issues, recently, studies were conducted to investigate promoting and supporting user well-being [18-22]. The importance of lighting design and its effect on well-being in the built environment was discussed by Altomonte et al. [23], as it affects and is affected by, for instance, aesthetic aspects of the environment, visual comfort, visual performance, and light effects beyond vision.

For commercial buildings, innovative luminaires with daylight-dependent dimming and wirelessly controlled occupancy sensors have already been on the market for decades. Available residential studies mainly focus on computational modelling (and validation) of control and behaviour (e.g., [24,25]). Wasted energy consumption by lighting in scenarios where light is on in unoccupied rooms at home may relate to behavioural goals and social needs. In this regard, Gerhardsson et al. [26] investigated various reasons behind electricity consumption by lighting in Swedish homes and concluded that keeping the lights on in unoccupied rooms serves a purpose such as preventing visual and aesthetic discomfort, providing safety, and making the home more inviting. The use of smart bulbs in homes is expected to increase from just over $2 \%$ in 2020 to nearly $8 \%$ in 2025 [27]. Even though statistical analysis predicts an increase in smart products in homes, it does not predict user acceptance and long-term usability. To benefit from lighting products' smart features and opportunities, households must accept, value, and use the products. According to Juric and Lindenmeier [28] 'consumer health concerns', 'performance expectancy', and 
'compatibility' are the major determinants of user behaviour in terms of user acceptance or resistance of smart lighting products. In office environments, many user acceptance studies have shown that automatic lighting control systems must be combined with some level of personal control (e.g., [29-31]), especially if the goal is to improve users' moods and their satisfaction with the lighting and the indoor environment [32].

Even though the number of smart lighting bulbs in homes is increasing, the opportunities for smart lighting systems in the residential environment and their effects on well-being and energy performance have not been widely explored. Therefore, this study aimed to review the literature regarding the effect of smart lighting systems on energy consumption and well-being in residential environments.

\section{Materials and Methods}

A literature review was conducted using two scientific literature databases: Scopus and Web of Science. Both databases are known for multidisciplinary peer-reviewed scientific literature and cover subject areas within the field of social, physical, health, and life science. The Preferred Reporting Items for Systematic Reviews and Meta-Analyses (PRISMA) statement $[33,34]$ was used for finding, reporting, and evaluating records. A PRISMA flow diagram was used to show the flow of information in the different stages of the review process, indicating the number of identified records, included and excluded, as well as the reasons for exclusion.

\subsection{Eligibility Criteria}

The eligibility criteria were based on the publication year (2001 onwards), subject area, document type (limited to peer-reviewed journal articles and reviews), and language (English). The publication year was set to studies published after 2001, as this was the year in which information about the additional functionality of photoreceptors in humans, largely responsible for light effects beyond vision, was published (e.g., [35-37]). Specific subject areas were excluded, as they resulted in finding irrelevant papers (material, economy, agriculture, earth/planetary, arts, pharmacology, chemistry, chemical engineering, bionic, immunology, business).

\subsection{Search Strategy}

The search process started by defining and categorising search terms, which were divided into four categories (see Table 1). The category 'Lighting system' was the main interest of this study and included all terms related to smart lighting. The synonyms for the term within this category were expanded numerous times during the search process. The category 'Context' provided the focus on residential environments. The category focusing on the outcomes of the studies, 'Light effects', was divided into 'Light effect on energy' and 'Light effect on well-being'. The latter two categories resulted in two search strings: (1) 'Lighting system' and 'Context' and 'Effects on energy' (2) 'Lighting system' and 'Context' and 'Effects on well-being'.

\subsection{Study Selection}

The search strings were applied within both databases, the results were merged, and duplicates were removed. Subsequently, three reviewers (the authors of the paper) screened the papers on title/keyword/abstract (TKA) individually by checking the relevance of the studies regarding smart lighting in a residential context on either well-being and/or energy. Papers were selected for a full paper review if two out of three reviewers assessed the paper as relevant. During the TKA screening process, papers were included in case they investigated the impact of a smart lighting system on energy and/or user well-being in a residential environment. Consequently, papers were excluded when they were conducted or proposed for a non-residential environment, were review papers, designed conceptual frameworks without reporting energy or well-being related issues, used non-smart systems, developed algorithms exclusively, focussed on user interaction with smart home appliances, 
focussed on user behaviour exclusively, or were conducted with a very specific user group (e.g., patients suffering from severe dementia). In case the results were technical papers or if the full paper was not available, the article was not included in the full-paper review. Additionally, the references of the found papers were screened to find more relevant studies.

Table 1. Search term category.

\begin{tabular}{cc}
\hline Categories & Keywords \\
\hline Lighting system & $\begin{array}{c}\text { (smart OR intelligent OR 'automated light*' OR ambient OR } \\
\text { dynamic OR tunable OR 'context light') AND (light* OR led*) } \\
\text { (residential OR 'living environment' OR apartment OR house } \\
\text { OR home OR 'living lab') }\end{array}$ \\
Light effect on energy & $\begin{array}{c}\text { synonyms (consumption OR efficient* OR optimis* OR } \\
\text { minimis* OR saving OR reduc*) AND (energy OR electricity) } \\
\text { ('well-being' OR 'visual comfort' OR 'user behaviour' OR } \\
\text { 'circadian rhythm' OR 'user satisfaction' OR 'visual effect' OR } \\
\text { iprgc OR mood OR health OR sleep OR performance OR } \\
\text { 'non-visual' OR 'wake-up' OR 'life quality') }\end{array}$ \\
\hline Lighting system AND Context AND Light effect on energy \\
Lighting system AND Context AND Light effect on well-being
\end{tabular}

\subsection{Data Collection Process}

Eligible studies were reviewed, and information was collected regarding the definition of a smart lighting system, the intended study aim, study characteristics, which included methodological characteristics (i.e., study type, measurement method(s), sample size, study duration, target group, and main outcome) and smart lighting system characteristics (i.e., the composition of the discussed/investigated system regarding the type of light source, communication protocol, control input, and sensor type).

\subsection{Developed Research Strategy}

The research strategy focused first on the documentation of smart lighting systems definition since the search terms were adapted multiple times during the search process. Secondly, it documented the studies' aims as defined in the papers, as searching for studies in two extensive domains (energy, well-being) may result in studies that fulfil the search criteria but serve a different purpose. Hence, categorisation was applied to enable the assessment and/or comparison of results from the topic/domain as well as the methodological perspective. Thirdly, the data collection process, as described in Section 2.4, was executed and documented, and, eventually, the results were discussed per category.

\section{Results}

\subsection{Study Selection}

In total, $1171(798+373)$ papers were selected after refining the databases' results during the identification phase (see Figure 2). Removing duplicates resulted in a total number of 683 papers. The TKA screening of these papers by three individual reviewers resulted in 71 papers for a full paper review. The screening of their references added two papers. In total, an additional 60 full papers were excluded as they did not fulfil the inclusion criteria, and eventually, 13 papers were found eligible for further analyses. 


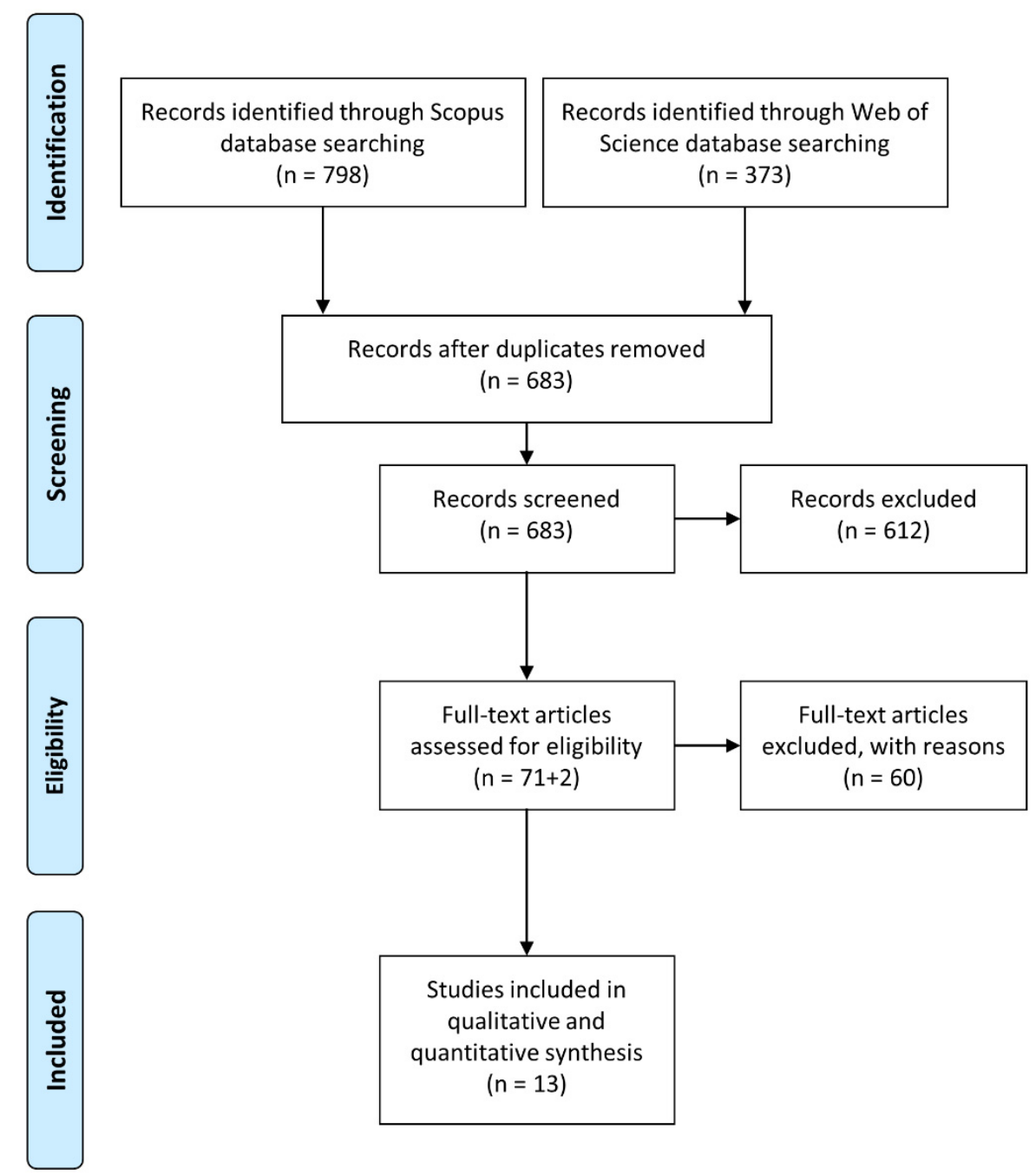

Figure 2. Flow diagram of the Preferred Reporting Items for Systematic Reviews and Meta-Analyses (PRISMA) used for reporting the systematic review process and the identified number of papers in each step. The last search was performed in March 2021.

\subsection{Definition of a Smart Lighting System}

As stated in the introduction, smart lighting systems include control, communication, and interconnection abilities, whereas smart lighting is a light source with controllability of certain light quality/quantity properties. Smart lighting includes smart light bulbs, which are illumination sources that include a processor to enable signal exchanges. Smart lighting systems were defined or named differently by the found studies, and in total, seven different synonyms were used for describing the proposed or investigated smart lighting system (see Table 2). Four studies used the term 'smart lighting' followed by three studies that used 'intelligent lighting'. Other definitions for smart lighting systems were 'automated', 'innovative', 'multi-objective', 'biodynamic', and 'context' lighting. It seems that the terms 'intelligent' and 'multi-objective' represent a kind of lighting system that, in addition to energy saving, can offer more services to the users, such as the adjustment of the lighting based on recognition of user activities [38-42]. 
Table 2. The terminology of the lighting systems of the 13 included studies.

\begin{tabular}{cc}
\hline Synonyms for 'Smart Lighting System' & References \\
\hline Smart lighting & Cimini et al. [43], Dikel et al. [44], Kumar et al. \\
& [45], Ringel et al. [46] \\
Intelligent lighting & Byun, Hong, Lee and Park [40], Izsó, Láng, \\
& Laufer, Suplicz and Horváth [41], Wang [42], \\
Automated lighting & Tang et al. [47] \\
Innovative lighting & Ahmadi-Karvigh et al. [48] \\
Multi-objective lighting & Frascarolo et al. [49] \\
Biodynamic lighting & Kwon and Lim [38] \\
LED Context lighting & Plischke et al. [50] \\
\hline
\end{tabular}

\subsection{Intended Study Aim}

The majority of the included studies (eight papers) aimed to design and develop a smart lighting system to reduce energy consumption and/or provide visual comfort for the occupants, for example, by the provision of empirical data as an input for an intelligent lighting system [41]. Other studies aimed to test and compare specific components of a smart lighting system [44], such as the standby energy consumption of smart LEDs, or the evaluation of the application area for smart lighting systems [45,46], for example, existing lighting recommendations for elderly/nursing homes [50]. Implementation and testing of a smart lighting system (in real-time) was the aim of only one study [48]. To enable a more equal comparison, studies were categorised, according to their intended aim, as 'component performance', 'system design/development', or 'application evaluation/implementation' (see Table 3). Additionally, the table shows that 10 studies aimed to investigate the impact on energy, eight studies on well-being and six targeted the implementation of both energy and well-being. An overview table with the intended aim, as described by the authors of the included studies, as well as a simple content analysis to support the categorisation is provided in Appendix A.

Table 3. Categorisation of the intended aim as described by the authors of the included 12 studies.

\begin{tabular}{|c|c|c|c|}
\hline Reference & Category & Energy & Well-Being \\
\hline Dikel, Li, Vuotari and Mancini [44] & Component performance & $x$ & \\
\hline Byun, Hong, Lee and Park [40] & System design or development & $x$ & $x$ \\
\hline $\begin{array}{l}\text { Cimini, Freddi, Ippoliti, } \\
\text { Monteriu and Pirro [43] }\end{array}$ & System design or development & $\mathrm{x}$ & $\mathrm{x}$ \\
\hline Frascarolo, Martorelli and Vitale [49] & System design or development & $x$ & $x$ \\
\hline $\begin{array}{l}\text { Izsó, Láng, Laufer, Suplicz and } \\
\text { Horváth [41] }\end{array}$ & System design or development & & $\mathrm{x}$ \\
\hline Kwon, Im and Lim [39] & System design or development & $x$ & $x$ \\
\hline Kwon and Lim [38] & System design or development & $x$ & $x$ \\
\hline $\begin{array}{l}\text { Tang, Kalavally, Ng } \\
\text { and Parkkinen [47] }\end{array}$ & System design or development & $x$ & \\
\hline Wang [42] & System design or development & & $x$ \\
\hline $\begin{array}{l}\text { Ahmadi-Karvigh, Ghahramani, } \\
\text { Becerik-Gerber and Soibelman [48] }\end{array}$ & $\begin{array}{l}\text { Application evaluation and } \\
\text { implementation }\end{array}$ & $\mathrm{x}$ & \\
\hline $\begin{array}{l}\text { Kumar, Kar, Warrier, } \\
\text { Kajale and Panda [45] }\end{array}$ & $\begin{array}{l}\text { Application evaluation and } \\
\text { implementation }\end{array}$ & $\mathrm{x}$ & $\mathrm{x}$ \\
\hline Ringel, Laidi and Djenouri [46] & $\begin{array}{l}\text { Application evaluation and } \\
\text { implementation }\end{array}$ & $x$ & \\
\hline Plischke, Linek and Zauner [50] & $\begin{array}{l}\text { Application evaluation and } \\
\text { implementation }\end{array}$ & & $\mathrm{x}$ \\
\hline
\end{tabular}

\subsection{Study Characteristics}

An evaluation of the study type and completeness of the included studies in different sections, documentation of dependent and independent variables, the inclusion of significant information regarding methodology (duration, sample size, location) was performed and the extracted data are shown in Table 4. Lighting characteristics are separately shown 
in Table 5. Selection criteria allowed studies published after 2001 (and before March 2021) and this resulted in one study published in each 2009, 2013, 2015, and 2020, two studies in 2014,2018 , and 2019, and three in 2017. Surprisingly, no studies were found to have been published between 2009 and 2013.

\subsubsection{Methodological Characteristics}

Study type-Studies were categorised into three different study types: (1) field study, (2) computational modelling (including algorithm development and computer simulations), and (3) laboratory study. In general, six papers included more than one study type; four studies included laboratory and computational modelling, and two studies included field and computational modelling. Three studies were conducted only as a laboratory study, two studies as a field study, and two as computational modelling (see Table 4).

Location-The research regarding smart lighting systems was conducted all over the world. Studies that investigated energy saving were conducted in and for California [48], Madrid [49], Singapore [45], South Korea [38,39], Malaysia [47], Germany and Algeria [46], and Canada [44]. Studies that solely investigated well-being were executed in Hungary [41] and Germany [50].

Residence type and size-In total, two studies were conducted in elderly homes [41,50]. Ahmadi-Karvigh, Ghahramani, Becerik-Gerber and Soibelman [48], and Frascarolo, Martorelli and Vitale [49] evaluated their studies in a real field setting, including two apartments and a full-scale house mock-up. Concerning the size of the residence, a simulation study [46] was conducted in a house with an area of $150 \mathrm{~m}^{2}$, while Tang, Kalavally, Ng and Parkkinen [47] included only a living room with an area of $\sim 20 \mathrm{~m}^{2}$. For all residences, the living room and bedroom were the most investigated spaces.

Sample size and target group-The sample size (human subjects or tested products) was reported in six studies; Ahmadi-Karvigh, Ghahramani, Becerik-Gerber and Soibelman [48] included two single-occupied apartments (the number of residents was not specified), and Izsó, Láng, Laufer, Suplicz and Horváth [41] involved 30 elderly people (aged 64-88). Plischke, Linek and Zauner [50] included 16 older people and 16 staff working in elderly homes. Wang [42] included 10 users in one room simulation and Ringel, Laidi and Djenouri [46] simulated one household with four family members. Dikel, Li, Vuotari and Mancini [44] tested 30 different types of smart LEDs for evaluation of their standby energy performance.

Duration-The duration of the conducted studies varied from one day to one year, depending on the aim and study type. Two studies conducted their experiment for 14 days [40,48]. Frascarolo, Martorelli and Vitale [49] measured energy consumption on an hourly and yearly basis. Izsó, Láng, Laufer, Suplicz and Horváth [41] conducted their experiment for half a day in an elderly home. Plischke, Linek and Zauner [50] and Kwon, Im and Lim [39] conducted their study for one day. Kwon and Lim [38] performed their study for four days, including one day in four different seasons.

\subsubsection{Lighting System Characteristics}

The overview of smart lighting characteristics revealed that there were three different types of light sources (CFL, LED, and Smart LED) in the proposed lighting systems, of which LED was the most common light source (see Table 5). Regarding communication network protocols, nine studies reported using wireless, and one study reported using wired protocols. Out of the nine studies that used wireless protocols, eight studies employed Zigbee and Xbee protocols [38-40,42,43,45,47,48], and one study used Wi-Fi and Bluetooth [44]. A wired Digital Addressable Lighting Interface (DALI) was used by one study [50]. Three studies did not report the network protocol for communication $[41,46,49]$. 
Table 4. Overview of the study characteristics and data extraction. References are organised alphabetically.

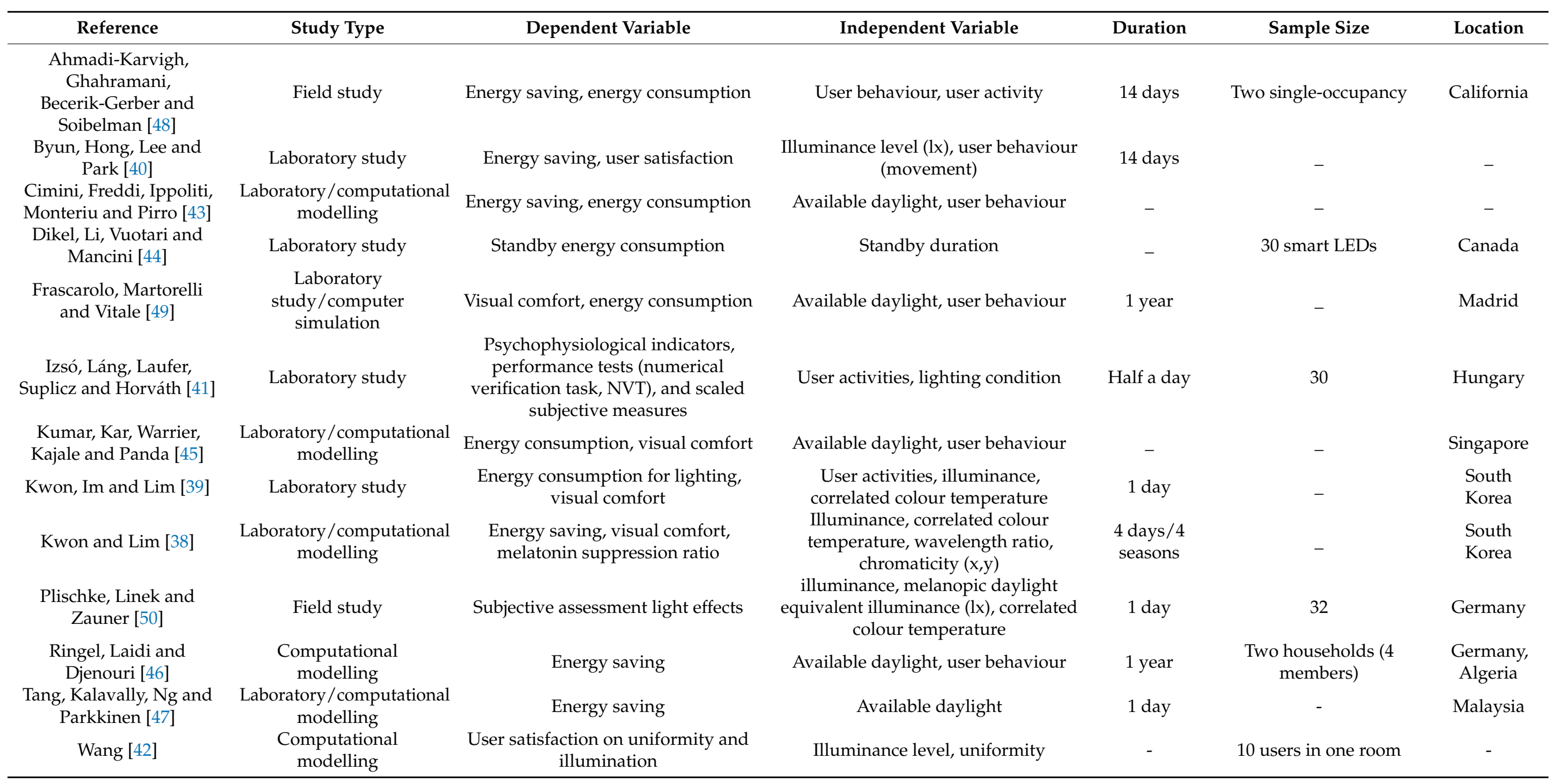


Table 5. Lighting system characteristics. References are organised alphabetically.

\begin{tabular}{|c|c|c|c|c|c|}
\hline Reference & Light Source & $\begin{array}{l}\text { Communication } \\
\text { Protocol }\end{array}$ & Control Input & Sensors & $\begin{array}{c}\text { Simulation } \\
\text { Software/Algorithm }\end{array}$ \\
\hline $\begin{array}{c}\text { Ahmadi-Karvigh, Ghahramani, } \\
\text { Becerik-Gerber and Soibelman [48] }\end{array}$ & - & XBee and ZigBee & $\begin{array}{l}\text { Activity recognition, } \\
\text { occupancy }\end{array}$ & $\begin{array}{l}\text { Plug meters, light sensors, } \\
\text { binary motion sensors }\end{array}$ & $\begin{array}{l}\text { Action and activity } \\
\text { recognition algorithm }\end{array}$ \\
\hline Byun, Hong, Lee and Park [40] & LED & ZigBee & $\begin{array}{c}\text { Occupancy, daylight } \\
\text { harvesting }\end{array}$ & Motion, light & $\begin{array}{l}\text { Light Intensity Control } \\
\text { Algorithm }\end{array}$ \\
\hline $\begin{array}{l}\text { Cimini, Freddi, Ippoliti, } \\
\text { Monteriu and Pirro [43] }\end{array}$ & LED string & ZigBee & Occupancy & $\begin{array}{l}\text { Motion, heat sink } \\
\text { temperature, light }\end{array}$ & Fault detection algorithm \\
\hline Dikel, Li, Vuotari and Mancini [44] & Smart LED bulbs & $\begin{array}{l}\text { Wi-Fi, Bluetooth, } \\
\text { hub/gateway }\end{array}$ & - & - & Yokogawa test software \\
\hline Frascarolo, Martorelli and Vitale [49] & Halogen, CFL, LED & - & $\begin{array}{c}\text { Manual + automatic, } \\
\text { occupancy, daylight } \\
\text { harvesting }\end{array}$ & Motion, light & Simulation software \\
\hline $\begin{array}{c}\text { Izsó, Láng, Laufer, } \\
\text { Suplicz and Horváth [41] }\end{array}$ & CFL & - & Manual, automatic & - & - \\
\hline $\begin{array}{l}\text { Kumar, Kar, Warrier, } \\
\text { Kajale and Panda [45] }\end{array}$ & LED & ZigBee & $\begin{array}{c}\text { Manual, automatic, and } \\
\text { hybrid }\end{array}$ & Motion, light & Control algorithm \\
\hline Kwon, Im and Lim [39] & LED panel & ZigBee, TCP/IP protocol & $\begin{array}{l}\text { Action recognition, } \\
\text { occupancy }\end{array}$ & $\begin{array}{l}\text { Motion (PIR), Piezoelectric } \\
\text { (pressure), power }\end{array}$ & - \\
\hline Kwon and Lim [38] & LED & ZigBee & Occupancy & $\begin{array}{l}\text { Spectral and RGB, smart } \\
\text { power, temperature, } \\
\text { humidity }\end{array}$ & $\begin{array}{l}\text { Matching algorithm of } \\
\text { chromaticity coordinates }\end{array}$ \\
\hline Plischke, Linek and Zauner [50] & CFL & DALI & Schedule & $\begin{array}{l}\text { DALI bus lighting } \\
\text { management system }\end{array}$ & - \\
\hline Ringel, Laidi and Djenouri [46] & $\begin{array}{l}\text { Regular and smart } \\
\text { lamp }\end{array}$ & - & $\begin{array}{l}\text { Manual, schedule, occupancy, } \\
\text { and daylight harvesting }\end{array}$ & Motion, light & $\begin{array}{c}\text { Energy Plus software, Design } \\
\text { Builder }\end{array}$ \\
\hline Tang, Kalavally, Ng and Parkkinen [47] & LED & Xbee, ZigBee module & Daylight harvesting & Light (smartphone camera) & $\begin{array}{l}\text { Luminaire control, } \\
\text { Closed-loop feedback }\end{array}$ \\
\hline Wang [42] & - & ZigBee & Occupancy & $\begin{array}{l}\text { Infrared (presence/absence), } \\
\text { illuminance }\end{array}$ & Lighting control algorithm \\
\hline
\end{tabular}


Table 6. Studies with energy-consumption/saving and well-being outcomes, including control input and light source. References are organised alphabetically.

\begin{tabular}{|c|c|c|c|c|c|}
\hline \multirow[b]{2}{*}{ Reference } & \multirow[b]{2}{*}{ Control Input } & \multirow[b]{2}{*}{ Light Source } & \multirow{2}{*}{$\begin{array}{c}\text { Energy } \\
\text { Outcome }\end{array}$} & \multicolumn{2}{|c|}{ Well-Being } \\
\hline & & & & Parameter & Outcome \\
\hline $\begin{array}{c}\text { Ahmadi-Karvigh, Ghahramani, } \\
\text { Becerik-Gerber and } \\
\text { Soibelman [48] }\end{array}$ & $\begin{array}{l}\text { Occupancy, Activity } \\
\text { recognition }\end{array}$ & - & $35 \%$ & & \\
\hline Byun, Hong, Lee and Park [40] & Daylight, Occupancy & LED (42 W) & $\sim 22 \%$ & Illumination intensity & Improvement of user satisfaction \\
\hline $\begin{array}{l}\text { Cimini, Freddi, Ippoliti, } \\
\text { Monteriu and Pirro [43] }\end{array}$ & Occupancy & LED string & $50 \%$ & Illuminance level & Preserving visual comfort \\
\hline $\begin{array}{l}\text { Dikel, Li, Vuotari } \\
\text { and Mancini [44] }\end{array}$ & - & Smart LEDs & $\begin{array}{c}\text { Standby consumption } 21 \\
\text { LEDs }<0.5 \mathrm{~W}\end{array}$ & & \\
\hline $\begin{array}{l}\text { Frascarolo, Martorelli } \\
\text { and Vitale [49] }\end{array}$ & Daylight, Occupancy & LED (4 W), CFL, Halogen & $75-93 \%$ & Illuminance level, luminance & Improvement of visual comfort \\
\hline $\begin{array}{c}\text { Izsó, Láng, Laufer, Suplicz and } \\
\text { Horváth [41] }\end{array}$ & Manual, automatic & CFL & & $\begin{array}{l}\text { Illuminance level, correlated colour } \\
\text { temperature }\end{array}$ & $\begin{array}{c}\text { Skin conductance no effect, high } \\
\text { illuminance }(5000 \text { lx) and broad CCT } \\
\text { range (2700-8000 K) increased NVT hit } \\
\text { ratio }\end{array}$ \\
\hline $\begin{array}{l}\text { Kumar, Kar, Warrier, Kajale } \\
\text { and Panda [45] }\end{array}$ & Daylight, occupancy & LED $(18 \mathrm{~W})$ & $60-70 \%$ & Illuminance level & Improvement of visual comfort \\
\hline Kwon, Im and Lim [39] & Daylight, activity recognition & LED panel & $35 \%$ & $\begin{array}{l}\text { Illuminance level, correlated colour } \\
\text { temperature }\end{array}$ & $\begin{array}{l}\text { User comfort activities according to } \\
\text { standards and Kruithof's curve }\end{array}$ \\
\hline Kwon and Lim [38] & $\begin{array}{l}\text { Occupancy, activity } \\
\text { recognition }\end{array}$ & LED panel & $2 \%$ & $\begin{array}{l}\text { Illuminance level, correlated colour } \\
\text { temperature, melatonin suppression }\end{array}$ & Health, emotion, performance \\
\hline Plischke, Linek and Zauner [50] & $\begin{array}{l}\text { Pre-programmed lighting } \\
\text { scenes, time-based schedule }\end{array}$ & CFL & & $\begin{array}{l}\text { Photopic illuminance, melanopic } \\
\text { daylight equivalent illuminance }\end{array}$ & $\begin{array}{l}\text { Suggestion for respondents' circadian } \\
\text { rhythm synchronisation with the } \\
\text { environment }\end{array}$ \\
\hline Ringel, Laidi and Djenouri [46] & Daylight, occupancy & Smart Bulb & $\sim 23 \%$ & & \\
\hline $\begin{array}{l}\text { Tang, Kalavally, Ng and } \\
\text { Parkkinen [47] }\end{array}$ & Daylight & RGB LED (40 W) & $54.7 \%$ & & \\
\hline Wang [42] & Occupancy & - & & Illuminance, uniformity & User satisfaction \\
\hline
\end{tabular}


Types of control range from the manual input of a control scheme in the system to more advanced occupancy-based ways of using activity recognition and daylight-linked adjustments. Among different types of control systems, occupancy control systems were used by seven studies, where other implemented control systems were 'daylight harvesting', 'timely schedule', and 'activity recognition' control strategies. Nine studies reported the use of sensors or a sensory system where they used different types of sensors for data acquisition depending on the study purpose and aim. Overall, seven different types of sensors (motion sensor, light sensor, pressure sensor, power sensor, temperature sensor, spectral sensor, and RGB sensor) were deployed for data acquisition in the proposed lighting systems. The use of computer software or algorithms was reported by 11 studies, of which four of them used lighting control algorithms to adjust the illuminance level. Other algorithms were reported for action and activity recognition, user satisfaction on uniformity detection, fault diagnosis, and chromaticity coordinates matching. The tools Energy Plus and Yokogawa Test Software were reported by two studies for the measurement of (standby) energy consumption. All studies that implemented algorithms/software reported results regarding energy saving/consumption.

\subsubsection{Outcomes Related to Energy Saving and Well-Being}

Of the 13 studies, 10 studies included energy outcomes, either as their sole or as a combined focus. The summary of the energy consumption/savings is reported in Table 6. All studies reported an overall energy saving percentage, except the study by Dikel, Li, Vuotari and Mancini [44], which looked at standby energy consumption only. The energy savings percentages range from 2 to $93 \%$ and the study characteristics in Table 6 show that there is a variety of control input options as well as types of light sources and their electric power consumption. For this review, only the overall energy saving information was extracted; therefore, it is unknown whether smart lighting system components (e.g., data communication, standby consumption) are included or excluded from the saving percentage. Of the 13 studies, nine studies included well-being outcomes, either as their sole or a combined focus, and the results are summarised in Table 6. The characteristics in the table show a large variety not only in control inputs and light sources but also in manipulated/measured parameters and investigated outcomes.

\section{Discussion}

This literature search resulted in finding 13 studies, which were difficult to compare for two main reasons. First, the definition of the 'smart lighting' studies was not comparable and the studies varied in required system components. Currently, no unambiguous definition of 'smart lighting system' exists, as various synonyms were used for describing an SLS, and its components are not extensively characterised. Disputably, a smart lighting system does not need to contain solid-state lighting or sensory technology for occupancy or daylight harvesting to function. Secondly, the 13 studies had varying aims that were categorised, focusing on 'component performance', 'system design/development', and 'application evaluation/implementation'.

\subsection{Component Performance}

Related to the intended aim of the study, only one study that fulfilled the search criteria, targeted system performance at a component level. Dikel, Li, Vuotari and Mancini [44] investigated the standby power consumption of different commercially available smart LED bulbs. Their results showed a standby consumption of (less than) $0.5 \mathrm{~W}$ per bulb. As mentioned in the introduction, components also used for (wireless) communication within an SLS are reported to have varying power use. Since residential environments have different (room) occupancy patterns and often a higher number of light sources compared to non-residential environments, consumption investigation at a component level can reveal relatively high saving percentages. This includes the type of light source, which is a crucial component when investigating energy performance. LED sources have higher 
efficacy compared to, for example, CFL sources. For commercial buildings, replacing CFLs with LEDs shows a reduction of energy demand by $43-52 \%$ [51]. The substitution of CFLs with LEDs resulted in 25-40\% electric energy savings per year in Scandinavian and German residential studies (e.g., [52,53]). For studies that focused on well-being, the type of light source seems less relevant if only the illuminance level is investigated. However, other qualities, like differences in the spectral power distribution of sources, have different effects on well-being-related variables, such as sleep or mood (e.g., [54]).

\subsection{System Design or Development}

There were nine of the 13 investigated studies that aimed to design or develop an SLS. Five of these studies [38-40,43,47] had an energy-related focus and used LED-light sources, whereas one study [48] focused on energy but did not specify the used light sources. Two studies focused on well-being; Izsó, Láng, Laufer, Suplicz and Horváth [41] used CFL sources for their investigations, and Wang [42] did not specify the used light sources. One study took both energy and well-being into account and used halogen, CFL, and LED sources. Its reported energy saving potential was $75-93 \%$, potentially being high due to the change from a (conventional) halogen/CFL system to a smart system, including LED sources [49].

The five exclusively energy-related studies with broadly comparable components showed a large variety of energy saving potentials ranging from 2 to $55 \%$. All five studies used LED light sources, but their power use was not always specified. Looking at the variety of communication protocols and control input variables, all five studies used the ZigBee protocol for data communication but get their input based on 'daylight levels' [47], 'occupancy' [43], 'daylight levels combined with activity recognition' [38], 'daylight levels combined with occupancy' [40], and 'occupancy combined with activity recognition' [39]. Tang, Kalavally, Ng and Parkkinen [47] controlled the smart lighting using daylight levels and reported an energy saving potential of 55\%, while the studies by Kwon and Lim [38] and Byun, Hong, Lee and Park [40] combined controlling by daylight with either activity recognition or occupancy. Both studies reported lower saving potentials. However, the geographical locations of the three studies and hence, their daylight climate, were different, with the study by Tang, Kalavally, Ng and Parkkinen [47] being executed close to the equator (Malaysia, $\sim 3^{\circ} \mathrm{N}$ ), which has equal daylengths year-round. Kwon and Lim [38]'s study was executed in South Korea $\left(\sim 37^{\circ} \mathrm{N}\right)$, with larger seasonal temperature, daylight, and daylength differences compared to Malaysia. Local climatic conditions have an influence on the occupancy of buildings, as levels of outdoor activity vary due to seasonality and weather conditions (e.g., [55]). Unfortunately, as two [40,43] of the five studies focusing on design or development did not specify a geographical location, a potential explanation for the difference in the reported energy saving potential related to the geographical location and the local daylight could not be explored.

Two studies with an aim related to SLS design or development [41,49] used CFL sources, which may be less crucial since their focus was predominantly on creating a visually comfortable environment or testing the impact of illuminance levels on well-being. Frascarolo, Martorelli and Vitale [49] investigated the impact of different light sources in a simulated house with a simulated user evaluation, but the study by Izsó, Láng, Laufer, Suplicz and Horváth [41] was a laboratory study in a simulated living room involving 30 participants varying both the illuminance and $\mathrm{CCT}$, and it tested the performance during a cognitive and visual task. The extremely different conditions and outcome variables make any comparison impossible. A third field study using CFL sources, focusing on well-being outcomes and involving 32 participants, aimed for application evaluation rather than the design or development of an SLS [50]. SLS development with simulated user evaluation was used in two studies [42,49]. Frascarolo, Martorelli and Vitale [49] aimed for visual comfort ' when and where it is needed (p. 217)' and Wang [42] simulated 10 potential user locations in a room. Both studies checked the agreement with visual comfort or performance criteria, but the results were inconclusive. 


\subsection{Application Evaluation and Implementation}

Even though six studies [38-41,43,49] indicated via their study aim that they predominantly focused on system development, the evaluation by users or the impact on users was included using outcome variables ranging from a subjective visual comfort assessment to physiological measurements. None of the studies was able to draw firm conclusions, and this was also the case for the studies that aimed for application evaluation and implementation. Plischke, Linek and Zauner [50] evaluated an SLS and its application area in three nursing homes. Kumar, Kar, Warrier, Kajale and Panda [45] focused on well-being outcomes and used LED sources, while Ringel, Laidi and Djenouri [46] focused on energy saving and used/compared regular and smart LED bulbs. The former combined laboratory experiments with computational modelling, while the latter simulated one year of energy consumption, and thus, with limited to no human interaction. Only two studies performed real-world field studies with human beings involved. The duration of the studies varied from one day [50] to 14 days [48], and this is seen, from both energy and well-being perspectives, too short a timeframe. If the effect of smart lighting on sleep quality-one significant marker of human well-being - is investigated, light exposure, together with differences in social schedules (workdays versus days off), may only manifest itself after taking multiple cycles of one working week.

\subsection{Study Limitations}

A literature review is suitable to provide an overview regarding a research area and state of knowledge. In this case, there were even two research areas, and 'energy' and 'wellbeing' are broad fields. Multiple studies were expected but only 13 papers indicated that published studies regarding the effects of smart lighting systems on energy consumption and well-being in residential environments were relevant.

One of the eligibility criteria was the limitation to peer-reviewed journal articles and reviews, excluding conference contributions. Even though the study characteristics of the currently included studies were already often incomplete, including conference papers would most likely not increase the methodological value but may have covered ongoing initiatives, such as pilot studies or the testing of prototypes.

The search concentrated on complete smart lighting systems, and only one study focused on the performance at the component level. Broadening the search strategy, including specific components such as 'communication protocol' or 'occupancy sensor' was not in the scope of this review.

The documentation of characteristics in general, and for lighting systems in particular, was limited to general study characteristics, including light source and control type. Neither the used instrumentalism for light and lighting measurements nor the documentation regarding the completeness of an energy saving potential calculation was considered.

The literature search was conducted using two databases. Even though Scopus and Web of Science are recognised as two major multidisciplinary literature databases and used by many research studies to find peer-reviewed articles, including more (topic-specific) databases could potentially have led to a (slightly) broader result.

\section{Conclusions and Recommended Action}

This study demonstrated that there is a need for an unambiguous definition of a 'smart lighting system' and its required components. The benefit of using an equivocal definition makes research results more accessible, and less confusion would be made with synonyms. A clear definition of the system composition enables comparison between components, systems, and full applications. The technical performance of a smart lighting system is essential to enable the quality rating of the system. Clear documentation of the type of light sources, communication protocols, control inputs, sensor types, and algorithms are necessary to conclude the quality and performance of the tested system. In situations involving information related to daylight, fundamental documentation of the geographical study location and the date and time of the execution are required. 
Aside from the technological quality assessments, high-quality (controlled) intervention studies on human performance and interaction measures enable the corroboration of possibilities and light effects regarding visual performance and visual comfort as well as effects beyond vision in personal environments, such as a residence. In particular, for investigating how light beyond vision is affected by a smart lighting system, a more detailed methodology is needed, including the documentation of light amount (level/intensity), light directionality, spectral power distribution, exposure duration, the timing of light exposure, and prior light exposure (e.g., [56]). It is crucial to follow available protocols for the proper communication of light exposure [57].

In parallel to cause-effect studies, studies focusing on acceptance of the technology or investigating user interactions with smart lighting systems are needed. This would allow for relating system performance to dimensions common in day-to-day situations and would deliver input for an optimal design of the residential smart lighting system. It may find the answer to questions regarding whether all rooms or only specific rooms should be equipped; whether smart lighting-related monitoring should be completely sensor-based. smartly balanced between system-controlled and human-controlled, or only task-specific (i.e., waking up), and in what way a smart lighting system should optimally interact with the local climate (weather) and situation (built environment).

Author Contributions: Conceptualisation: M.A. and G.F.; methodology: M.A., G.F. and M.S.; formal analysis: M.S. and M.A.; investigation, M.S. and M.A.; data curation, M.A. and M.S.; writing—original draft preparation, M.A., M.S. and G.F.; writing—review and editing, M.A. and G.F.; visualization, M.S. and M.A.; supervision, M.A. and G.F.; project administration, M.A.; funding acquisition, M.A. and G.F. All authors have read and agreed to the published version of the manuscript.

Funding: This research was funded by the Swedish Energy Agency (project P45185) and Smart Housing Småland.

Data Availability Statement: Not applicable.

Acknowledgments: The authors would like to acknowledge assistance by the JU library staff and the valuable comments by the reviewers and editors of the journal of Sustainability.

Conflicts of Interest: The authors declare no conflict of interest.

\section{Appendix A. Overview of Aims as Stated in the Studies}

Table A1. Intended aims, as described by the authors of the included studies and simple content analysis to support the categorisation (text in underline style) as well as the research area: energy (highlighted dark grey) and well-being (highlighted).

\begin{tabular}{|c|c|c|c|}
\hline Reference & Aim & Outcome & Category \\
\hline [44] & $\begin{array}{l}\text { 'This study focuses solely on the standby power } \\
\text { consumption of smart LED bulbs' (p. 72) }\end{array}$ & Energy & Component performance \\
\hline [40] & $\begin{array}{c}\text { 'This paper proposes an intelligent household LED lighting } \\
\text { system considering energy efficiency and } \\
\text { user satisfaction' (p. 70) }\end{array}$ & Energy, well-being & $\begin{array}{l}\text { System design or } \\
\text { development }\end{array}$ \\
\hline [43] & $\begin{array}{l}\text { 'The goal of this work is to develop a smart light-emitting } \\
\text { diode lighting system for industrial and domestic use with } \\
\text { several advantages over conventional systems, namely } \\
\text { energy saving, high reliability, and visual comfort of } \\
\text { interior lighting' (p. 1696). }\end{array}$ & Energy, well-being & $\begin{array}{l}\text { System design or } \\
\text { development }\end{array}$ \\
\hline
\end{tabular}


Table A1. Cont.

\begin{tabular}{|c|c|c|c|}
\hline Reference & Aim & Outcome & Category \\
\hline [49] & $\begin{array}{l}\text { 'The primary goal of the project is to design a lighting } \\
\text { system that provides the highest visual comfort and } \\
\text { conserves energy for different uses and furniture layouts' } \\
\text { (p. 217). }\end{array}$ & Energy, well-being & $\begin{array}{l}\text { System design or } \\
\text { development }\end{array}$ \\
\hline [41] & $\begin{array}{l}\text { 'The objective of these studies was to } \\
\text { provide sound empirical data for an intelligent, } \\
\text { adaptive home lighting system to be created for the } \\
\text { elderly' (p. 349). }\end{array}$ & Well-being & $\begin{array}{l}\text { System design or } \\
\text { development }\end{array}$ \\
\hline [39] & $\begin{array}{c}\text { 'This study aims to design LED context lighting system that } \\
\text { automatically recognises the location and acts of a user in } \\
\text { residential areas and creates an appro priate lighting } \\
\text { environment' (p. 1). }\end{array}$ & Energy, well-being & $\begin{array}{l}\text { System design or } \\
\text { development }\end{array}$ \\
\hline [38] & $\begin{array}{l}\text { 'This study suggests a multi-objective context-adaptive } \\
\text { natural lighting system that changes the lighting } \\
\text { environment according to various control objectives } \\
\text { ( health, emotion, performance, and energy savings )' } \\
\text { (p. 61) }\end{array}$ & Energy, well-being & $\begin{array}{l}\text { System design or } \\
\text { development }\end{array}$ \\
\hline [47] & $\begin{array}{l}\text { 'This paper proposes a smart home lighting system with } \\
\text { enhanced security features together with a very economical } \\
\text { solution for daylight harvesting using the user's personal } \\
\text { smartphone' (p. 369) }\end{array}$ & Energy & $\begin{array}{l}\text { System design or } \\
\text { development }\end{array}$ \\
\hline$[42]$ & $\begin{array}{l}\text { 'Considering the illumination and uniformity of light, an } \\
\text { intelligent lighting control algorithm based on gradient } \\
\text { descent was designed' (p. 1231) }\end{array}$ & Well-being & $\begin{array}{l}\text { System design or } \\
\text { development }\end{array}$ \\
\hline [45] & $\begin{array}{l}\text { 'This paper presents implementation of a smart LED } \\
\text { lighting system utilising different energy-efficient } \\
\text { techniques without compromising the visual comfort of } \\
\text { occupants' (p. 173). }\end{array}$ & Energy, well-being & $\begin{array}{l}\text { Application evaluation and } \\
\text { implementation }\end{array}$ \\
\hline [48] & $\begin{array}{l}\text { 'We introduce a framework to detect occupant activities } \\
\text { and potential wasted energy consumption and } \\
\text { peak-hour usage that could be shifted to non-peak hours } \\
\text { in real-time.' (p. 146) }\end{array}$ & Energy & $\begin{array}{l}\text { Application evaluation and } \\
\text { implementation }\end{array}$ \\
\hline [50] & $\begin{array}{l}\text { 'A goal of this evaluation was to check whether the } \\
\text { recommendations of the specification DIN SPEC } 67600 \text { in } \\
\text { three nursing homes were met and another goal was if } \\
\text { effectiveness of the lighting on residents and nursing staff } \\
\text { can be determined' (p. 123). }\end{array}$ & Well-being & $\begin{array}{l}\text { Application evaluation and } \\
\text { implementation }\end{array}$ \\
\hline [46] & $\begin{array}{l}\text { 'The aim of our study is to determine which of the multiple } \\
\text { macroeconomic benefits of energy efficiency could be } \\
\text { realised by and promoted to a single-family homeowner } \\
\text { willing to make a modest investment in smart home } \\
\text { technology' (p. 3). }\end{array}$ & Energy & $\begin{array}{l}\text { Application evaluation and } \\
\text { implementation }\end{array}$ \\
\hline
\end{tabular}

\section{References}

1. Solaimani, S.; Keijzer-Broers, W.; Bouwman, H. What we do-And don't-Know about the Smart Home: An analysis of the Smart Home literature. Indoor Built Environ. 2013, 24, 370-383. [CrossRef]

2. Rossi, M. LEDs and New Technologies for Circadian Lighting. In Research for Development; Springer: Cham, Switzerland, 2019; pp. 157-207.

3. Schubert, E.F.; Kim, J.K. Solid-State Light Sources Getting Smart. Science 2005, 308, 1274-1278. [CrossRef] 
4. Alobaidy, H.A.; Mandeep, J.; Nordin, R.; Abdullah, N.F. A Review on ZigBee Based WSNs: Concepts, Infrastructure, Applications, and Challenges. IJEETC 2020, 9, 10.

5. Van Bommel, W.J.M. Interior Lighting: Fundamentals, Technology and Application; Springer International Publishing: Berlin/Heidelberg, Germany, 2019.

6. Chew, I.; Karunatilaka, D.; Tan, C.P.; Kalavally, V. Smart lighting: The way forward? Reviewing the past to shape the future. Energy Build. 2017, 149, 180-191. [CrossRef]

7. Haq, M.A.U.; Hassan, M.Y.; Abdullah, H.; Rahman, H.A.; Abdullah, M.P.; Hussin, F.; Said, D.M. A review on lighting control technologies in commercial buildings, their performance and affecting factors. Renew. Sust. Energ Rev. 2014, 33, $268-279$. [CrossRef]

8. Pandharipande, A.; Caicedo, D. Smart indoor lighting systems with luminaire-based sensing: A review of lighting control approaches. Energy Build. 2015, 104, 369-377. [CrossRef]

9. De Bakker, C.; Aries, M.; Kort, H.; Rosemann, A. Occupancy-based lighting control in open-plan office spaces: A state-of-the-art review. Build. Environ. 2017, 112, 308-321. [CrossRef]

10. Nagy, Z.; Yong, F.Y.; Frei, M.; Schlueter, A. Occupant centered lighting control for comfort and energy efficient building operation. Energy Build. 2015, 94, 100-108. [CrossRef]

11. Galasiu, A.D.; Newsham, G.R.; Suvagau, C.; Sander, D.M. Energy Saving Lighting Control Systems for Open-Plan Offices: A Field Study. LEUKOS 2007, 4, 7-29. [CrossRef]

12. Higuera, J.; Hertog, W.; Perálvarez, M.; Polo, J.; Carreras, J. Smart lighting system ISO/IEC/IEEE 21451 compatible. IEEE Sens. J. 2015, 15, 2595-2602. [CrossRef]

13. Jennings, J.; Colak, N.; Rubinstein, F. Occupancy and Time-Based Lighting Controls in Open Offices. J. Illum. Eng. Soc. 2002, 31, 86-100. [CrossRef]

14. Roisin, B.; Bodart, M.; Deneyer, A.; D'Herdt, P. Lighting energy savings in offices using different control systems and their real consumption. Energy Build. 2008, 40, 514-523. [CrossRef]

15. Zou, H.; Zhou, Y.; Jiang, H.; Chien, S.C.; Xie, L.; Spanos, C.J. WinLight: A WiFi-based occupancy-driven lighting control system for smart building. Energy Build. 2018, 158, 924-938. [CrossRef]

16. Von Neida, B.; Maniccia, D.; Tweed, A. An Analysis of the Energy and Cost Savings Potential of Occupancy Sensors for Commercial Lighting Systems. J. Illum. Eng. Soc. 2001, 30, 111-125. [CrossRef]

17. Yun, G.Y.; Kim, H.; Kim, J.T. Effects of occupancy and lighting use patterns on lighting energy consumption. Energy Build. 2012, 46, 152-158. [CrossRef]

18. Kim, K.-M.; Kim, Y.-W.; Oh, S.-T.; Lim, J.-H. Development of a natural light reproduction system for maintaining the circadian rhythm. Indoor Built. Environ. 2019, 29, 132-144. [CrossRef]

19. Choi, K.; Shin, C.; Kim, T.; Chung, H.J.; Suk, H.J. Awakening effects of blue-enriched morning light exposure on university students' physiological and subjective responses. Sci. Rep. 2019, 9, 1-8. [CrossRef] [PubMed]

20. Figueiro, M.G.; Hunter, C.M.; Higgins, P.A.; Hornick, T.R.; Jones, G.E.; Plitnick, B.; Brons, J.; Rea, M.S. Tailored lighting intervention for persons with dementia and caregivers living at home. Sleep Health 2015, 1, 322-330. [CrossRef]

21. Papatsimpa, C.; Linnartz, J.-P. Personalized Office Lighting for Circadian Health and Improved Sleep. Sensors 2020, $20,4569$. [CrossRef]

22. Davis, K.; Owusu, E.B.; Marcenaro, L.; Feijs, L.; Regazzoni, C.; Hu, J. Effects of Ambient Lighting Displays on Peripheral Activity Awareness. IEEE Access 2017, 5, 9318-9335. [CrossRef]

23. Altomonte, S.; Allen, J.; Bluyssen, P.M.; Brager, G.; Heschong, L.; Loder, A.; Schiavon, S.; Veitch, J.A.; Wang, L.; Wargocki, P. Ten questions concerning well-being in the built environment. Build. Environ. 2020, 180, 106949. [CrossRef]

24. Muratori, M.; Roberts, M.C.; Sioshansi, R.; Marano, V.; Rizzoni, G. A highly resolved modeling technique to simulate residential power demand. Appl. Energy 2013, 107, 465-473. [CrossRef]

25. Widén, J.; Wäckelgård, E. A high-resolution stochastic model of domestic activity patterns and electricity demand. Appl. Energy 2010, 87, 1880-1892. [CrossRef]

26. Gerhardsson, K.M.; Laike, T.; Johansson, M. Leaving lights on-A conscious choice or wasted light? Use of indoor lighting in Swedish homes. Indoor Built Environ. 2020, 1420326X20908644. [CrossRef]

27. Statista Comfort and Lighting-Worldwide IStatista Market Forecast. Available online: https://www.statista.com/outlook/392/ 100/comfort-and-lighting/worldwide (accessed on 3 February 2021).

28. Juric, J.; Lindenmeier, J. An empirical analysis of consumer resistance to smart-lighting products. Light. Res. Technol. 2018, 51, 489-512. [CrossRef]

29. Moore, T.; Carter, D.; Slater, A. A study of opinion in offices with and without user controlled lighting. Light. Res. Technol. 2004, 36, 131-144. [CrossRef]

30. Newsham, G.R.; Aries, M.B.; Mancini, S.; Faye, G. Individual control of electric lighting in a daylit space. Light. Res. Technol. 2008, 40, 25-41. [CrossRef]

31. Duijnhoven, J. Personal Lighting Conditions of Office Workers-The Input for Intelligent Systems to Optimize Subjective Alertness. Ph.D. Thesis, Technische Universiteit Eindhoven, Eindhoven, The Netherlands, 2019.

32. Newsham, G.; Veitch, J.; Arsenault, C.; Duval, C. Effect of dimming control on office worker satisfaction and performance. In Proceedings of the IESNA Annual Conference, Tampa, Florida, 25-28 July 2004; pp. 19-41. 
33. Liberati, A.; Altman, D.G.; Tetzlaff, J.; Mulrow, C.; Gotzsche, P.C.; Ioannidis, J.P.; Clarke, M.; Devereaux, P.J.; Kleijnen, J.; Moher, D. The PRISMA statement for reporting systematic reviews and meta-analyses of studies that evaluate health care interventions: Explanation and elaboration. PLoS Med. 2009, 6, e1000100. [CrossRef]

34. PRISMA PRISMA Statement. Available online: http://www.prisma-statement.org/ (accessed on 3 February 2021).

35. Berson, D.M.; Dunn, F.A.; Takao, M. Phototransduction by Retinal Ganglion Cells That Set the Circadian Clock. Science 2002, 295, 1070-1073. [CrossRef] [PubMed]

36. Thapan, K.; Arendt, J.; Skene, D.J. An action spectrum for melatonin suppression: Evidence for a novel non-rod, non-cone photoreceptor system in humans. J. Physiol. 2001, 535, 261-267. [CrossRef]

37. Brainard, G.C.; Hanifin, J.P.; Greeson, J.M.; Byrne, B.; Glickman, G.; Gerner, E.; Rollag, M.D. Action Spectrum for Melatonin Regulation in Humans: Evidence for a Novel Circadian Photoreceptor. J. Neurosci. 2001, 21, 6405. [CrossRef]

38. Kwon, S.Y.; Lim, J.H. Multi-objective context-adaptive natural lighting system. Energy Build. 2017, 144, 61-73. [CrossRef]

39. Kwon, S.-Y.; Im, K.-M.; Lim, J.-H. LED Context Lighting System in Residential Areas. Sci. World J. 2014, 2014, 16. [CrossRef] [PubMed]

40. Byun, J.; Hong, I.; Lee, B.; Park, S. Intelligent household LED lighting system considering energy efficiency and user satisfaction. IEEE Trans. Consum. Electron. 2013, 59, 70-76. [CrossRef]

41. Izsó, L.; Láng, E.; Laufer, L.; Suplicz, S.; Horváth, Á. Psychophysiological, performance and subjective correlates of different lighting conditions. Light. Res. Technol. 2009, 41, 349-360. [CrossRef]

42. Wang, L. Home intelligent lighting control system based on wireless sensor. J. Eng. Des. Technol. 2020, 18, 1231-1240. [CrossRef]

43. Cimini, G.; Freddi, A.; Ippoliti, G.; Monteriu, A.; Pirro, M. A Smart Lighting System for Visual Comfort and Energy Savings in Industrial and Domestic Use. Electr. Power Compon. Syst. 2015, 43, 1696-1706. [CrossRef]

44. Dikel, E.E.; Li, Y.E.; Vuotari, M.; Mancini, S. Evaluating the standby power consumption of smart LED bulbs. Energy Build. 2019, 186, 71-79. [CrossRef]

45. Kumar, A.; Kar, P.; Warrier, R.; Kajale, A.; Panda, S.K. Implementation of Smart LED Lighting and Efficient Data Management System for Buildings. Energy Procedia 2017, 143, 173-178. [CrossRef]

46. Ringel, M.; Laidi, R.; Djenouri, D. Multiple benefits through smart home energy management solutions-A simulation-based case study of a single-family-house in Algeria and Germany. Energies 2019, 12, 1537. [CrossRef]

47. Tang, S.; Kalavally, V.; Ng, K.Y.; Parkkinen, J. Development of a prototype smart home intelligent lighting control architecture using sensors onboard a mobile computing system. Energy Build. 2017, 138, 368-376. [CrossRef]

48. Ahmadi-Karvigh, S.; Ghahramani, A.; Becerik-Gerber, B.; Soibelman, L. Real-time activity recognition for energy efficiency in buildings. Appl. Energy 2018, 211, 146-160. [CrossRef]

49. Frascarolo, M.; Martorelli, S.; Vitale, V. An innovative lighting system for residential application that optimizes visual comfort and conserves energy for different user needs. Energy Build. 2014, 83, 217-224. [CrossRef]

50. Plischke, H.; Linek, M.; Zauner, J. The opportunities of biodynamic lighting in homes for the elderly: Melanopic measurements and experiences from three senior citizen facilities. Curr. Dir. Biomed. Eng. 2018, 4, 123-126. [CrossRef]

51. Principi, P.; Fioretti, R. A comparative life cycle assessment of luminaires for general lighting for the office-Compact fluorescent (CFL) vs. Light Emitting Diode (LED)—A case study. J. Clean. Prod. 2014, 83, 96-107. [CrossRef]

52. Qu, K.; Chen, X.; Ekambaram, A.; Cui, Y.; Gan, G.; Økland, A.; Riffat, S. A novel holistic EPC related retrofit approach for residential apartment building renovation in Norway. Sustain. Cities Soc. 2020, 54, 101975. [CrossRef]

53. Mills, B.; Schleich, J. Household transitions to energy efficient lighting. Energy Econ. 2014, 46, 151-160. [CrossRef]

54. Stefani, O.; Freyburger, M.; Veitz, S.; Basishvili, T.; Meyer, M.; Weibel, J.; Kobayashi, K.; Shirakawa, Y.; Cajochen, C. Changing color and intensity of LED lighting across the day impacts on circadian melatonin rhythms and sleep in healthy men. J. Pineal Res. 2020, 70, e12714.

55. Tucker, P.; Gilliland, J. The effect of season and weather on physical activity: A systematic review. Public Health 2007, 121, 909-922. [CrossRef]

56. Khademagha, P.; Aries, M.B.C.; Rosemann, A.L.P.; van Loenen, E.J. Implementing non-image-forming effects of light in the built environment: A review on what we need. Build. Environ. 2016, 108, 263-272. [CrossRef]

57. Spitschan, M.; Stefani, O.; Blattner, P.; Gronfier, C.; Lockley, S.W.; Lucas, R.J. How to Report Light Exposure in Human Chronobiology and Sleep Research Experiments. Clocks Sleep 2019, 1, 24. [CrossRef] 